\title{
It's not Okay! The Importance of Educating our Population Taking Prescribed Controlled Substances, Regarding the Risks for Dependency and Addiction
}

\author{
Christine Marie Davies ${ }^{1, *}$ and Paul F Franzese ${ }^{2}$ \\ ${ }^{1}$ Doctor of Nursing Practice, Family Nurse Practitioner, Tenured Nursing Professor at Dominican College, Orangeburg, New York, USA \\ ${ }^{2}$ Registered Nurse, Retired Narcotics Captain, New York City Police Department, USA
}

*Corresponding author: Christine Marie Davies, Doctor of Nursing Practice, Family Nurse Practitioner, Tenured Nursing Professor at Dominican College, Orangeburg, 3 Park Avenue, Congers, New York 10920, USA, Tel: (845) 721-2159; E-mail: christine.davies@dc.edu

Received: 26 Nov, 2020 | Accepted: 02 Jun, 2021 | Published: 14 Jun, 2021

Citation: Davies CM, Franzese PF (2021) It's not Okay! The Importance of Educating our Population Taking Prescribed Controlled Substances, Regarding the Risks for Dependency and Addiction. J Epidemiol Public Health Rev 6(2): dx.doi.org/10.16966/2471-8211.215

Copyright: (C) 2021 Davies CM, et al. This is an open-access article distributed under the terms of the Creative Commons Attribution License, which permits unrestricted use, distribution, and reproduction in any medium, provided the original author and source are credited.

\begin{abstract}
This article will focus on the major narcotic, and opioid prescription epidemic that is overpowering our nation destroying lives, families, and resulting in death. As healthcare professionals, nursing educators, family nurse practitioner, and Doctor of Nursing Practice with prescription privileges in New York State, in our scopes of practice we always inform and educate all individuals we care for concerning all medications they are prescribed. While we have sought to achieve this educational goal in our professional capacity, as human beings with medical issues like anyone else, we have also been the patients. Our life altering experiences resulted in extensive hospital stays and physical rehabilitation therapy, which required the need of opiate, controlled medications during our inpatient and outpatient recoveries. What we found alarming about the state of our care was not the management of the injuries we sustained, but the lack of education that should have been directed towards us and our families, regarding the use and discontinuance of prescribed opioids upon discharge. We personally observed that there is an overall lack of education in this area. As healthcare practitioners, we are all on the front line and serve to ensure safety of all individuals and the diverse populations we serve. Everyone in healthcare beginning with prescribers, medical staff, and nursing staff, must have the knowledge to explain to the patient and family what a controlled substance is, as well as the inherent risk of becoming addicted, tapering methods, signs and symptoms of withdrawal, and a basic understanding of the dangers that become apparent with self-administration of controlled substances upon discharge. Without proper education, many community populations are at risk for harm. Education is indeed the key and a priority at the forefront of medicine and nursing that ensures patients and their families have a thorough understanding of all the risks associated with these potent narcotics.
\end{abstract}

Keywords: Prevention; Education/lack of education; Narcotics; Opioids and substances; Addiction; Harm; Patients right to know; Healthcare; Mortality; Morbidity

\section{Introduction}

As healthcare practitioners and parents, we are very concerned about the devastating global problem of narcotics addiction. "At least 2 million people have an Opioid Use Disorder (OUD) involving prescription opioids, and almost 600,000 have an OUD associated with heroin" [1]. Addiction to controlled substances, specifically prescription narcotics such as Oxycontin, Oxycodone, Vicodin, Morphine, Fentanyl, Codeine, Tramadol, and Hydromorphone are highly addictive which has resulted in individuals seeking heroin when the prescriptions are no longer available [1]. Global concern is rising every day, and affects the health, wellbeing, and social and economic welfare of all societies worldwide" [1]. Addiction does not discriminate; it is a fear many individuals faced when prescribed opioids for pain. Our main focus in this article is on education, prevention and outreach regarding prescribed controlled substances. We will be examining many factors including mortality, morbidity, addiction, abuse, and knowledge deficit related to the lack of education and instructions on discharge by health care providers in hospitals or offices. Anecdotally, we will share our experiences and what we observed as a major need for more education, specifically on the dangers of discharging individuals' home on high dosages of opioids such as Oxycontin and Oxycodone. We have personally been prescribed high dosages of Oxycontin and Oxycodone. "Surgery is among the most common indications for opioid initiation" [2]. As a result of our personal experiences as a patient, and our duty to helping people daily through our professions, we feel it is necessary to express our feelings and experiences. Christine Davies underwent four major extensive lumbar and cervical spinal fusion surgeries in a three-year period that consisted of hardware, and bone grafts. During my postoperative recoveries, I was prescribed oxycontin, and oxycodone which was administered frequently throughout the day, evening and night to aid in pain relief. Upon discharge after each major spinal surgery, I was transferred to an in-patient physical rehabilitation facility for approximately one month after each surgery. During these times, I was prescribed high doses of oxycontin and oxycodone around the 
clock. Upon discharge, I was prescribed high doses of oxycontin and oxycodone to take on my own or have my family administer to me [3]. My family or myself were not provided with education on these narcotics, nor was the risk of addiction to these medications discussed at all throughout all in-patient services. Paul Franzes was involved in a work-related accident, which required several surgeries and inpatient physical rehabilitation. He was also prescribed high doses of oxycontin and oxycodone. Upon his discharge with these prescribed medications, no education was provided to his family or him on the risk of addiction, and withdrawal symptoms. Both Paul and I as healthcare professionals knew the risk of addiction however; we were under the influence of these medications that affected us from thinking soundly. When the time came at different periods in our lives attempting to eliminate taking these potent narcotics on a daily basis, we both went through an unsupervised, unsafe, and unbearable withdrawal from these medications that could have been life threatening to us. Our goal is to inform the public and bring more awareness to populations of all ages seeking medical care, some of whom may have been involved in accidents, undergone surgery, or are living with chronic pain, that "It is Not Okay", to stay on narcotics for long periods of time. The danger of addiction involves developing a drug tolerance whereby the prescribed dose no longer has the intended effect on the body. When the physician stops writing the prescription, or eventually stops raising the dosage, many individuals seek other drugs in an attempt to satiate their perceived need for relief. These drugs may be legal prescription drugs illegally sold on the street, or illegal drugs such as heroin. As street value for narcotics is expensive, many turn to heroin or alternative drugs to achieve a similar effect, which can prove deadly. Sadly, many individuals do not realize until they are addicted to the opiates, and other related narcotic substances until they attempt to stop them therefore "It is Not Okay" to stay on these substances for long period of time. Many individuals are unaware and uninformed about the resources available to them to help combat the addiction.

Many are familiar with the phrase, "ignorance is bliss", and for this case we feel it applies to the approach taken towards prescriptions for controlled substances. Generations of individuals feel that if the physician prescribes the medication, they are safely able to use it without concern. For many people, their fears of personal addiction are allayed by the fact that many doctors will continue to refill their prescriptions for a long period of time. At some point, however, two things may happen: either doctors may finally choose not to fill these prescriptions indefinitely, or patients may find that the prescription itself is simply not achieving its function anymore. This second alternative leaves them craving relief, and may lead them to seek other drugs such as heroin. While the situations we have discussed are not representative of all possibilities, they represent a portion, and serve to reinforce the severity of the drug epidemic that currently exists in our nation.

\section{Statistics}

"Nearly 450,000 people died from overdoses involving any opioid, including prescription and illicit opioids, from 1999-2019" [1]. "The misuse of and addiction to opioids including prescription pain relievers, heroin, and synthetic opioids such as fentanyl is a serious national crisis that affects public health as well as social and economic welfare" [4]. According to the World Drug Report [5], "It is estimated that between 26.4 million and 36 million people abuse opioids worldwide". In addition, "there are an estimated 2.1 million people in the United States suffering from substance abuse disorders related to prescription opioid pain relievers, and an estimated 467,000 addicted to heroin" [6]. The CDC found in 2014 that the leading cause of death among 25-64 year old Americans was unintentional poisoning [1]. The consequences of this abuse have been devastating and are on the rise, as are the number of unintentional overdose deaths from prescription pain relievers. In 2015 as the opioid epidemic continued to soar there were 47.7 million individuals (12 years old and older) that used or misused prescription drugs [5]. In 2015, there were 52,404 drug overdose deaths reported. The amount of drug related deaths in the United States in 2016 was 64,000 [7]. These statistics have increased by $21 \%$ since 2015 and quadrupled since 1999 [4]. "According to the CDC, in 2012, health care providers wrote 259 million prescriptions for painkillers, enough for every American adult to have a bottle of pills" [1].

In examining opioid abuse, it is important to understand the how and why of people becoming addicted. Matoo summarizes it well, stating: "Prescription opioid pain medications such as Oxycontin and Vicodin are mostly prescribed for the treatment of moderate to severe pain and are currently among the most commonly abused drugs in the United States" $[8,9]$. Research now suggests that abuse of these drugs may open the door to heroin abuse [4]. Opioids act by attaching to specific proteins called opioid receptors, which are found on nerve cells in the brain, spinal cord, gastrointestinal tract, and other organs in the body. When these drugs attach to their receptors, they reduce the perception of pain and can produce a sense of well-being; however, they can also produce drowsiness, mental confusion, nausea, and constipation" [10].

On the other hand, controlled substances including opioids do have their place. "It is important to also understand that opioids when monitored under the direction of trained medical staff can help reduce human suffering and relieve pain" [5], thus the reason doctors prescribe these medications from the start [11]. The reasons are often legitimate and run the spectrum from an individual suffering intolerable pain from a disease or accident, to the post-surgical patient who often has a painful period of rest and rehabilitation ahead. However, with the repeated administration of opioid drugs (legal or illegal), the production of endogenous opioids is inhibited, which accounts in part for the discomfort that ensues when the drugs are discontinued (i.e., withdrawal) [11]. Adaptations of the opioid receptors' signaling mechanisms have also been shown to contribute to withdrawal symptoms [4]. The withdrawal symptoms can be severe and individuals can become very ill, often not understanding what is happing to them. In many cases, once they take the opioid medication the symptoms subside and they begin to feel better $[12,13]$.

Despite being health care professionals, and seemingly aware of the risks, this happened to us. After numerous surgeries, and severe pain, we found ourselves taking opioids under the ubiquitous moniker of $\mathrm{PRN}$, or as necessary. The period of waiting for the next dose ensued, and like many, we found ourselves in need of that higher dosage to compensate for our body adapting to the medication. From this experience, we learned that if this happened to us, as staunch advocates against overuse and misuse of prescription opioids, it could happen to you. Often in life, when we are most susceptible to the initial need for opioids, we are not in the correct mind set given the severity of our pain. The signs and symptoms of addiction are there, but they become masked behind the relief that is achieved. Education, as we will explore further, is paramount, and without family who are educated on what to look for, the signs of addiction will go unnoticed or dismissed [14-16].

One of the key factors that have contributed to the severity of the current prescription drug abuse problem includes the drastic increases in the number of prescriptions issued. "Data from the United States suggest that there has been an increase in the amount of opioids 
dispensed following minor surgical procedures and that many US patients receive more opioids than necessary to treat their shortterm pain" [17]. "Excessive post-operative opioid prescribing has been associated with increased risks of drug diversion, new long-term opioid use, and the development of opioid use disorder" [18-25]. To put this in perspective, the United States accounts for almost 100 percent of the world total for Hydrocodone and 81 percent for Oxycodone [26,27].

\section{Prevention and Education}

Spoth RL, et al. [28] succinctly summarizes the difficulty we face by stating: "Because prescription drugs are safe and effective when used properly and are broadly marketed to the public, the notion that they are also harmful and addictive even before abuse occurs can be a difficult one to convey. Thus, we need focused research to generate targeted communication strategies that effectively address this problem. Reaching this goal may be more complex than developing and deploying effective programs for the prevention of abuse of illegal drugs. However, "good prevention messages based on scientific evidence will be difficult to ignore". The key message we want to convey is that short time usage can lead to addiction, and legal use can become illegal use. Therefore, it is critical to implement stringent preventive strategies and follow through education $[1,5]$. Education is a critical component of any effort to curb the abuse of prescription medications and must target every segment of society, including doctors. The National Institute on Drug Abuse is advancing addiction awareness, prevention, and treatment in primary care practices, including the diagnosis of prescription drug abuse, having established four Centers of Excellence for Physician Information. Intended to serve as national models, these Centers target physicians-in-training, including medical students and resident physicians in primary care specialties (e.g., internal medicine, family practice, and pediatrics) [8]. NIDA has developed, in partnership with the Office of National Drug Control Policy (ONDCP), two online continuing medical education courses on safe prescribing for pain and managing patients who abuse prescription opioids [11]. "To date combined; these courses have been completed over 80,000 times. Additionally, NIDA is directly reaching out to teens with its Peer Initiative, an online education program that aims to discourage prescription drug abuse among teens, by providing factual information about the harmful effects of prescription drug abuse on the brain and body" [28].

Doctors, however, cannot handle the task alone, and NIDA can only handle so much. There must be reinforcement from every cog in the wheel to keep our healthcare system running. This includes registered nurses, who often provide education to patients upon discharge and on exit from doctors' offices, to pharmacies. The emphasis of education must not lie solely on the intended actions, side effects, and adverse effects of these medications, but also on the risk of dependency and addiction. With patient consent, education should be provided to family as well, advising them of the signs and symptoms to look for as their loved one begins taking these medications. Additionally, patients using a prescribed controlled substance for a set period of time, such as three months, must attend a mandatory educational session with their healthcare provider before a new prescription is issued [29].

As healthcare professionals, it is our duty to convey just how dangerous these medications can be if not taken correctly. Educational literature must be provided to every patient and their families. While most opioid medications will contain warnings regarding care when operating machinery, there is no mention of care to avoid dependency. Education on dependency and addiction are a vital part of the prescription process that is too often overlooked [30]. From the doctor issuing the prescription to the pharmacist filling and handing it to the patient, all must share the responsibility providing patients and families with adequate education with these medications [31].

Many of our current policies are reactive, and even at that, we are lacking. It has been proposed that a national self-help support line be established and included on the issuance of all prescription medications. Looking at pharmacies, CVS, the largest pharmacy company in the United States, has taken steps to combat providers who are "exhibiting extreme patterns of prescribing high-risk drugs" [32]. They have worked to suspend the dispensing privileges of these providers. In addition, CVS has implemented mandated policy changes, such as the Mandatory Utilization of Prescription Monitoring Program, that prevents patients from "shopping" for the same prescriptions from multiple providers, by creating a database that tracks prescribing of controlled substances both locally and across state lines [1].

These measures, while proactive in combating abuse, do not mitigate the preceding factor of dependency and addiction. Anecdotally, having gone into a CVS and filled a prescription for a controlled substance for the first time, the containing paper bag had included literature marked "Counsel" [1]. I was asked as I was with any other medication if I had any questions, and upon glancing at the line forming behind me, and stating there were none, I simply paid and left. While I was asked to show identification prior to issuance, the above situation was the extent of my experience. While there would have undoubtedly been a pharmacist available to answer questions if I had any, the fact that we currently do not require the pharmacist to meet with each patient prescribed a controlled substance and explain the risks is a measure we should change [30]. As an analogy, while laws on firearms licensing vary from state to state (i.e. from NY to NJ), many states require safety training before issuance. Simply looking at our CDC statistics relative to unintentional deaths from poisonings, controlled substances pose a substantial risk when the safety risks are not understood, just as the mishandling of firearms does. It is imperative that we formulate a plan that allows our pharmacies nationwide to offer a more comprehensive "counsel" for prescribed controlled substances; educating not only on the pharmacologic information, but also the very important inherent high risks associated with using these medications [33]. In addition, a national self-support line could help avert the escalating process from legal to illegal drug use [31].

\section{Conclusion}

Our nation is faced with one of the largest growing epidemics that have overpowered our population. Individuals who abused prescribed controlled substances legally prescribed, illegally shared, and sold relate this epidemic to accidental drug overdoses [7]. "Opioid addiction is driving this epidemic with overdoses the leading cause of accidental deaths in the United States [7]. In 2015, there were 20,101 overdose deaths related to prescription pain relievers, and 12,990 overdose deaths related to heroin" [7].

As healthcare practitioners we have a duty to the patients we care for and must follow standards of care to treat their pain. Although we have emphasized the negative effects of controlled prescribed substances, when used within the guidelines they can be essential in alleviating pain when patients are monitored. When administering any type of controlled substances we must educate all patients and families because, "It is important that patients receive appropriate pain treatment with careful consideration of the benefits and risks of treatment options" [31]. The Centers for Disease Control implemented guidelines and checklists for prescribing opiates to "to improve communication between clinicians and patients about the risks and benefits of opioid therapy for chronic pain, improve the safety and 
effectiveness of pain treatment, and reduce the risks associated with long-term opioid therapy" [31].

The World Health Report states, "We support the development and implementation of multipronged, evidence-based strategies that minimize the intrinsic risks of opioid medications and make effective, long-term treatments available" [5]. We wholeheartedly agree that from physician to pharmacy, we must make changes that educate and identify patients about the risks of opioid dependency and addiction [8]. We must ensure a multipronged checklist regarding education at all levels, and we must ensure that patients are equipped with the knowledge and support systems, such as a national self-help support line, that is provided to them both in writing and verbally, so they may tackle and question their controlled substance usage 24 hours a day [8]. Because the longevity and continued or repeated use of these medications are predicating factors for dependency and addiction, families must be knowledgeable about identifying their signs and symptoms [7]. And when possible, we must consider instituting mandatory consultations, in compliance with HIPAA, at some time between prescription to issuance, that require a family member or healthcare provider (i.e. home health care aide for an elderly patient) to be present with the patient and equally informed [7].

To conclude, our nation is overpowered by a growing epidemic of ever-growing proportions, as the very healthcare system we depend on fails to provide if the safety nets we depend on are not adequate [34]. While we have proactive and reactive measures in place, they are not enough in light of the severe risk that everyone from our youth to our elderly undertake when they engage in the seemingly innocuous activity of filling a legally prescribed controlled substance at their local pharmacy [31]. Because we are aware of how usage can spiral in a downward trajectory that leads to addiction, illegal use, and death, educational methods that can help create an understanding of, and prevent addiction in the first place, should be our utmost concern and priority [31].

As the young and wise Malala Yousafzai said, "There are many problems, but I think there is a solution to all these problems; it's just one, and it's education" $[8,35]$. Together, we must institute policy and protocol that protects our patients, and reiterates that indeed, "It's Not Okay," to take opioid medications for long periods of time. As healthcare providers, each and every one of us has a responsibility to advocate for our patients, educate them and families because it is through this lens of caring that we can provide the safety measures to proactively combat addiction and dependency and enable our patients to lead safe and fulfilling lives [31].

\section{References}

1. Rudd RA, Seth P, David F, Scholl LI (2016) Increases in Drug and Opioid-Involved Overdose Deaths-United States, 2010-2015. MMWR Morb Mortal Wkly Rep 65: 1445-1452.

2. Pasricha SV, Tadrous M, Khuu W, Juurlink DN, Mamdani MM, et al. (2018) Clinical indications associated with opioid initiation for pain management in Ontario, Canada: a population-based cohort study. Pain 159: 1562-1568.

3. Packiasabapathy S, Horn N, Sadhasivam S (2018) Genetics of perioperative pain management. Curr Opin Anaesthesiol 31: 749755.

4. National Institute on Drug Abuse (2018) Opioid Overdose Crisis.

5. United Nations Office on Drugs and Crime (2012) World Drug Report 2012.
6. Substance Abuse and Mental Health Services Administration, Rockville MD (2013) Results from the 2012 National Survey on Drug Use and Health: Summary of National Findings. NSDUH Series H-46. HHS Publication SMA 13-4795.

7. Hedegaard H, Chen LH, Warner M (2014) QuickStats: Rates of Drug Poisoning Deaths Involving Heroin,* by Selected Age and Racial/ Ethnic Groups-United States, 2002 and 2011. MMWR 63: 595.

8. Dowell D, Haegerich TM, Chou R (2016) CDC Guideline for Prescribing Opioids for Chronic Pain-United States, 2016. MMWR Recomm Rep 65: 1-49.

9. Van Zee A (2009) The promotion and marketing of oxycontin: commercial triumph, public health tragedy. Am J Public Health 99: 221-227.

10. National Survey on Drug Use and Health, Rockville MD (2016) Substance Abuse and Mental Health Services Administration 2016. NSDUH Series H-51. HHS Publication SMA 16-4984.

11. Callinan CE, Neuman MD, Lacy KE, Gabison C, Ashburn MA (2017) The Initiation of Chronic Opioids: A Survey of Chronic Pain Patients. J Pain 18: 360-365.

12. Bicket MC, Long JJ, Pronovost PJ, Alexander GC, Wu CL (2017) Prescription Opioid Analgesics Commonly Unused After Surgery: A Systematic Review. JAMA Surg 152: 1066-1071.

13. Brat GA, Agniel D, Beam A, Yorkgitis B, Bicket M, et al. (2018) Postsurgical prescriptions for opioid naive patients and association with overdose and misuse: retrospective cohort study. BMJ 360: j5790.

14. Wetzel M, Hockenberry J, Raval MVb (2018) Interventions for Postsurgical Opioid Prescribing: A Systematic Review. JAMA Surg 153: 948-954.

15. Hartford LB, Van Koughnett JAM, Murphy PB, Vogt KN, Hilsden RJ, et al. (2019) Standardization of Outpatient Procedure (STOP) Narcotics: A Prospective Non-Inferiority Study to Reduce Opioid Use in Outpatient General Surgical Procedures. J Am Coll Surg 228: 8188.

16. Sekhri S, Arora NS, Cottrell H, Baerg T, Duncan A, et al. (2018) Probability of Opioid Prescription Refilling after Surgery: Does Initial Prescription Dose Matter? Ann Surg 268: 271-276.

17. Wunsch H, Wijeysundera DN, Passarella MA, Neuman MD (2016) Opioids Prescribed after Low-Risk Surgical Procedures in the United States, 2004-2012. JAMA 315: 1654-1657.

18. Brummett CM, Waljee JF, Goesling J, Moser S, Lin P, et al. (2017) New Persistent Opioid Use after Minor and Major Surgical Procedures in US Adults. JAMA Surg 152: e170504.

19. Manjiani D, Paul DB, Kunnumpurath S, Kaye AD, Vadivelu N (2014) Availability and utilization of opioids for pain management: global issues. Ochsner J 14: 208-215.

20. Berterame S, Erthal J, Thomas J, Fellner S, Vosse B, et al. (2016) Use of and barriers to access to opioid analgesics: a worldwide, regional, and national study. Lancet 387: 1644-1656.

21. Seya MJ, Gelders SF, Achara OU, Milani B, Scholten WK (2011) A first comparison between the consumption of and the need for opioid analgesics at country, regional, and global levels. J Pain Palliat Care Pharmacother 25: 6-18.

22. von Elm E, Altman DG, Egger M, Pocock SJ, Gøtzsche PC, et al. (2007) The Strengthening the Reporting of Observational Studies in Epidemiology (STROBE) statement: guidelines for reporting observational studies. Ann Intern Med 147: 573-577. 
23. Feinberg AE, Chesney TR, Srikandarajah S, Acuna SA, McLeod RS, et al. (2018) Opioid Use After Discharge in Postoperative Patients: A Systematic Review. Ann Surg 267: 1056-1062.

24. Soelberg CD, Brown RE Jr, Du Vivier D, Meyer JE, Ramachandran BK (2017) The US Opioid Crisis: Current Federal and State Legal Issues. Anesth Analg 125: 1675-1681.

25. Onishi E, Kobayashi T, Dexter E, Marino M, Maeno T, et al. (2017) Comparison of Opioid Prescribing Patterns in the United States and Japan: Primary Care Physicians' Attitudes and Perceptions. J Am Board Fam Med 30: 248-254

26. Mattoo SK, Singh SM, Bhardwaj R, Kumar S, Basu D, et al. (2009) Prevalence and correlates of epileptic seizure in substance-abusing subjects. Psychiatry Clin Neurosci 63: 580-582.

27. International Narcotics Control Board (2009) Report of the International Narcotics Control Board for 2008. United Nations publication.

28. Spoth RL, Redmond C, Trudeau L, Shin C (2002) Longitudinal substance initiation outcomes for a universal preventive intervention combining family and school programs. Psychol Addict Behav 16: 129-134.
29. Tay EMY, Roberts DM (2018) A spotlight on the role, use, and availability of codeine and the implications faced. Expert Rev Clin Pharmacol 11: 1057-1059.

30. Brennan TA (2017) Working Together to Combat Prescription Drug Abuse. CVS.

31. MacKinnon JI (2016) Tighter regulations needed for over-thecounter codeine in Canada. Can Pharm J (Ott) 149: 322-324.

32. National Institute of Health (2017) National Institute on Drug Abuse (NIDA). The NIH Almanac.

33. Drug Enforcement Administration, Department of Justice (2014) Schedule of controlled substances: placement of tramadol into schedule IV. Final rule. Fed Regist 79: 37623-37630

34. Wide-ranging online data for epidemiologic research (WONDER) (2020) Atlanta, GA: CDC, National Center for Health Statistics.

35. CBC Radio (2013) In Her Words: 6 Quotes from the Malala Yousafzai interview. The Current. 